\title{
Anal sphincter responses after perianal electrical stimulation
}

\author{
EJNER PEDERSEN, BENNY KLEMAR, HENRIK DAA SCHRØDER, JESPER TØRRING \\ From the Neurological Laboratory, Department of Neurology, Aarhus Kommunehospital, Aarhus, Denmark
}

SUMMARY By perianal electrical stimulation and EMG recording from the external anal sphincter three responses were found with latencies of 2-8, 13-18 and 30-60 ms, respectively. The two first responses were recorded in most cases. They were characterised by constant latency and uniform pattern, were not fatigued by repeated stimulation, were most dependent on placement of stimulating and recording electrodes, and always had a higher threshold than the third response. The third response was constantly present in normal subjects. It had the longest EMG response and the latency decreased with increasing stimulation to a minimum of 30-60 ms. This response represented the clinical observable spinal reflex, "the classical anal reflex". The latencies of the two first responses were so short that they probably do not represent spinal reflexes. This was further supported by the effect of epidural anaesthesia which left the first responses unaffected but abolished the classical anal reflex. The origin of the two first responses is discussed and models involving antidromal impulse propagation in the efferent fibre as the afferent limbs of the responses are proposed.

The anal reflex, always found in normal subjects, was originally described by Rossolimo' ${ }^{1}$ as a contraction of the anus in response to stimulation of the perianal skin or mucosa. Not much was added to his description before quantitative methods were introduced, including electrical stimulation and EMG recording of the reflex response. By such studies ${ }^{2}$ we were able to confirm that the reflex was constantly present in normal persons and that its latency decreased with increasing stimulation to a minimum latency of $30-60 \mathrm{~ms}$, average $50 \mathrm{~ms}$ (SD 10.5). We stimulated generally with a train of five electrical square wave pulses, which is most appropriate for eliciting exteroceptive reflexes such as the flexor reflex. ${ }^{3}$ However, the short distance between our stimulating and recording electrodes generally saturated the amplifier, and we therefore blocked it for the first $10-20 \mathrm{~ms}$. In this period Henry and Swash ${ }^{4}$ reported action potentials in the anal reflex in normal subjects with a latency of 8-9 ms using stimulation with one pulse of $0 \cdot 1-0 \cdot 2 \mathrm{~ms}$ duration of the

Address for reprint requests: Dr Ejner Pedersen, Department of Neurology, Aarhus Kommunehospital 8000 Aarhus C, Denmark

Received 16 September 1981 and in revised form 26 December 1981

Accepted 25 January 1982 perianal skin and recording with electrodes inserted into the external anal sphincter in the midline position posterior to the anal verge. Later they described an anal response with a latency in normal subjects within the range $5-11.3 \mathrm{~ms}^{5}$

This paper reports our extended studies of the anal sphincter responses by perianal electrical stimulation with a single pulse and also including midline placement of the recording electrode as used by Henry and Swash.

\section{Materials and methods}

The electrical stimulation was led to the patient by a programming unit allowing independent alterations of the number, separation between and duration of the pulses and a constant current output unit. The stimuli were applied to the skin by a pencil electrode. In our extended studies one pulse with a duration of $0.2 \mathrm{~ms}$ was used. The impedance of the stimulating electrodes were brought below $5 \mathrm{k} \Omega$. The EMG of the anal sphincter was obtained by bipolar intramuscular needle electrodes inserted through the skin just outside the anocutaneous junction into the external anal sphincter, or as used by Henry and Swash, in the midline position posterior to the anal verge. The signals from the electrodes were fed through EMG amplifiers to our data recording equipment. ${ }^{\circ}$

Ten normal subjects were investigated with recording electrodes placed in the midline, and more than 60 persons including normal subjects and spastic patients have so far been investigated with placement as used in our previous 
work, and all were stimulated with one electrical pulse and also studied for early responses.

\section{Results}

In the 10 normal subjects investigated with midline electrodes, the classical anal reflex was recorded in all, but faster responses only in five of them.

In the persons investigated with our usual placement of recording electrodes outside the midline, the fast responses were found in most of the subjects, but movements of the recording and stimulating electrodes were often necessary to obtain these reactions. The classical anal reflex was recorded in all, but minimum latency was not obtainable in many cases with single pulse stimulation.

The early responses could generally be separated into two parts. The first with a latency of $2-8 \mathrm{~ms}$ and the second with a latency of 13-18 ms. In some of the subjects only one of the early responses was recorded, but in most subjects both were present, but generally with different thresholds. In all cases the early responses had a higher threshold than the classical anal reflex. In some cases also minor later responses were recorded, but they were not systematically investigated. The early responses had a very constant latency (fig 1) and the electrical pat-

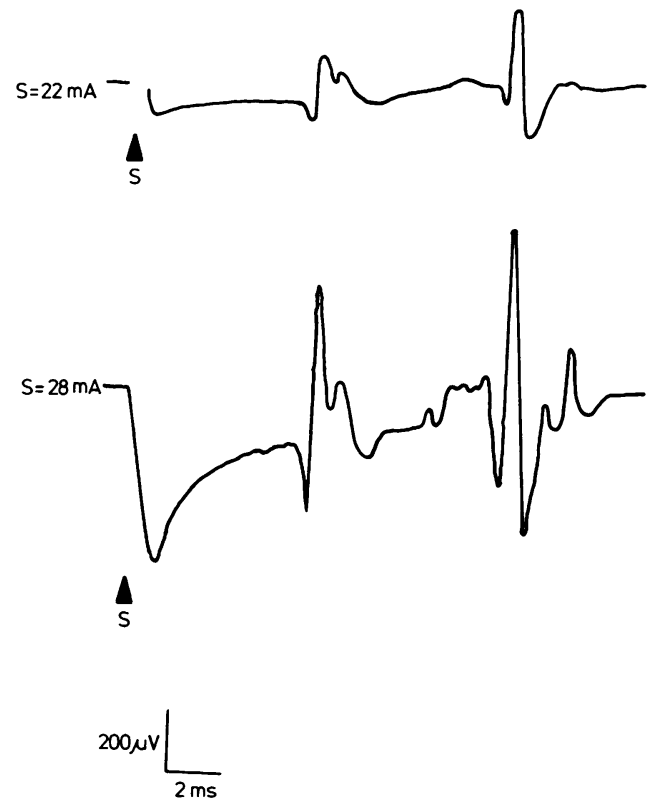

Fig 1 EMG from the anal sphincter after perianal electrical stimulation with one pulse of $0.2 \mathrm{~ms}$ duration. The reflex in the upper trace is elicited by stimulus intensity near the threshold, the reflex in the lower trace by higher stimulation. $s=$ stimulation tern was uniform when a certain placement of stimulation and recording electrodes was used and generally they showed no signs of fatigue (fig 2). The classical anal reflex had the longest response (fig 3 ). In the elicitation of the early responses, especially the fastest, stimulation on the same side as the recording electrodes were found necessary. By midline recording electrodes, the fast reactions usually could be elicited by stimulation only on one side.

We had the opportunity to investigate these responses in a patient before and during epidural anaesthesia indicated for surgical intervention. Before the anaesthesia a very powerful classical anal reflex was found with a threshold of $2.5 \mathrm{~mA}$, but this response was abolished during anaesthesia, even after stimulation with $85 \mathrm{~mA}$. The early responses

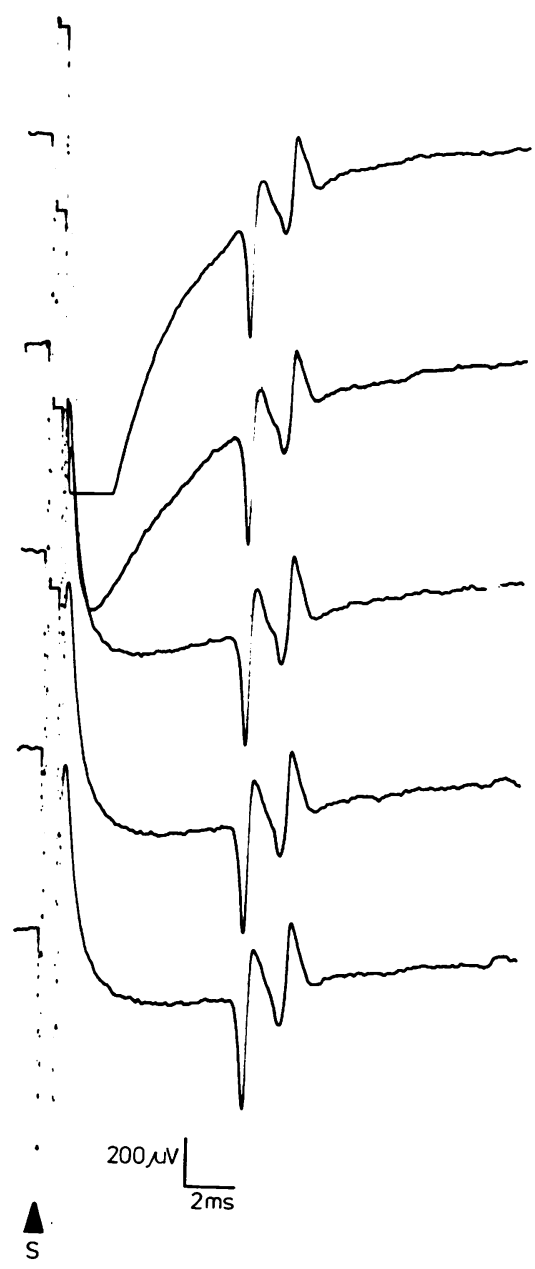

Fig 2 Consecutive responses elicited with 5 s interval. Each stimulation with one pulse and $0.2 \mathrm{~ms}$ duration. $s=30 \mathrm{~mA}$ 


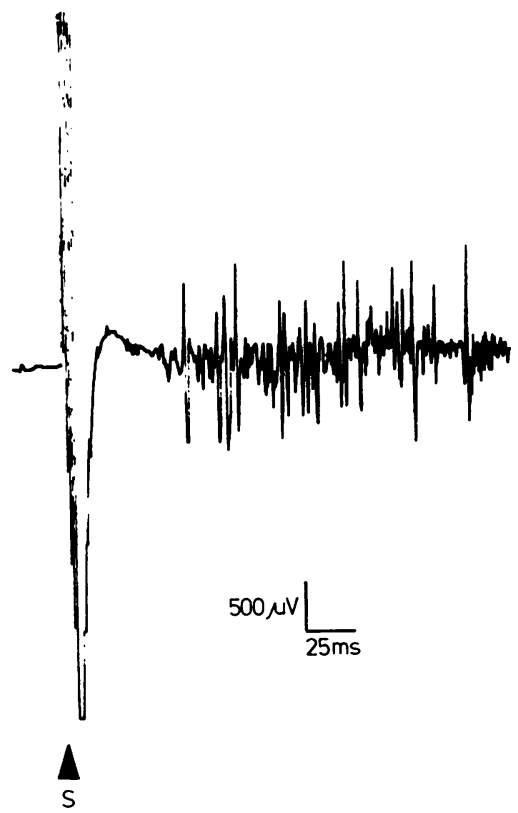

Fig 3 EMG from the anal sphincter after perianal electrical stimulation with 5 pulses of 0.5 ms duration and separated by $1 \mathrm{~ms}$. $\mathrm{s}=6 \mathrm{~mA}$

were unchanged during anaesthesia with a threshold of $15 \mathrm{~mA}$ and a latency of $4 \mathrm{~ms}$.

\section{Discussion}

Responses with a minimum latency of $30-60 \mathrm{~ms}$ can be recorded in all normal subjects and spastic patients after perianal electrical stimulation. ${ }^{2}$ This reflex had the lowest threshold and the longest EMG response and represents the clinical observable spinal reflex originally described by Rossolimo. ${ }^{1}$ The reflex can also be elicited by stimulation by a single electrical pulse, but with a much higher current, and the minimum latency can not be reached in all persons.

To elucidate the nature of these responses, the theoretical peripheral transit time can be of value. According to morphological ${ }^{7}$ and electrophysiological studies ${ }^{8}$ the sphincters are innervated mainly from $S_{1}, S_{2}$, and $S_{3}$. From measurements on five skeletons we have estimated the length of the pudendal nerve from the $S_{2}$ segment situated at the level of the body of the 12th thoracic vertebra to the anal sphincter to be at least $35-37 \mathrm{~cm}$ of which about $20 \mathrm{~cm}$ represents intravertebral distance. This is in contrast to the findings of Henry $e t l^{5}$ who measured the distance in two cadavers and found it to be 20 and $28 \mathrm{~cm}$, respectively. The conduction velocity in the efferent fibres of the pudendal nerve has been recorded to be about $56 \mathrm{~m} / \mathrm{s}$ by Chantraine. ${ }^{9}$ Using this figure, like Henry $e t$ al, both for efferents and afferents results in a minimal peripheral transit time of about $12.5 \mathrm{~ms}$. If a conduction velocity of about $70 \mathrm{~m} / \mathrm{s}$ for cutaneous sensory nerves is used for the afferents the theoretical peripheral transit time is about $11 \mathrm{~ms}$, and if the involved afferents are proprioceptive fibres with a conduction velocity of about $120 \mathrm{~m} / \mathrm{s}$, it is about 9.5 $\mathrm{ms}$. A spinal source for the responses seen 2-8 ms after stimulation thus is excluded. This is strongly supported by the observations during epidural anaesthesia which left the fast reactions unaffected, but abolished the classical anal reflex.

A direct stimulation of the efferent nerves resulting in muscle contraction might be a possibility, as stimulation with electrical pulses of a duration of $0.2 \mathrm{~ms}$ or less differentially activate the efferent nerves. ${ }^{10}$ Such an explanation of the first reaction, however, is unlikely since efferent nerves with a much slower conduction velocity than is known would be involved. In our laboratory it was demonstrated in rats that some pelvic muscle motoneurons innervate two different muscles, so peripheral axon collaterals exist in this group of neurons. Moreover, the presence of peripheral extra-muscular collaterals of the axons of motoneurons innervating the gastrocnemius muscle has been demonstrated physiologically in man. ${ }^{11}$ The fastest anal sphincter response could be due to a direct nerve stimulation with impulses travelling antidromic in the efferent nerve to the point of branching and then anterograde in the collateral division of the pudendal nerve. This would be in accordance with the high threshold level found and the very constant latency and uniformity of the electrical pattern, when a certain placement of stimulating and recording electrodes was used. It would also fit the lack of habituation; the strictly ipsilateral appearance and the presence in spite of epidural anaesthesia.

The latencies of the second anal sphincter response might give time for a spinal reflex, but other explanations can be put forward. Gogan et al ${ }^{12}$ analysed direct excitatory interactions between spinal motoneurons of the cat by antidromic stimulation of efferents and proposed that the mechanisms behind the results observed might involve either electric interaction between neighbouring motoneurons or excitatory recurrent collaterals between motoneurons (fig 4). The existence of direct synaptic connection between cat spinal motoneurons via recurrent axon collaterals has been demonstrated by Cullheim et al, ${ }^{13}$ although sphincter motoneurons were not analysed. In the rat and cat extensive direct contacts between neurons innervat- 
References

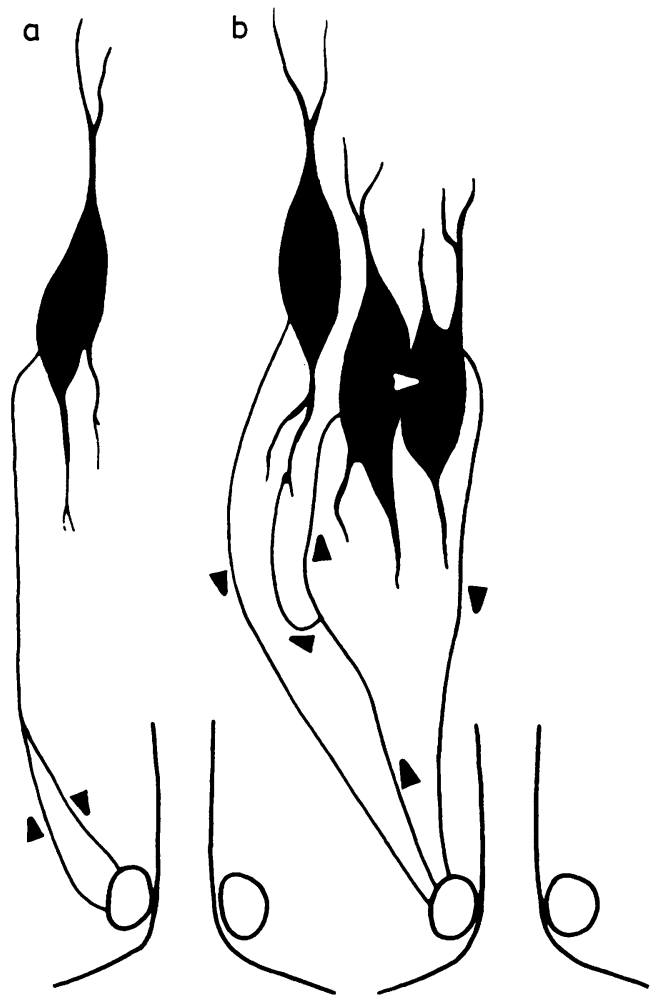

Fig 4 Arrows indicating possible routes of the impulse in the furst (a) and second (b) fast response. In (a) the impulse travels antidromically to the point of branching and then down the other collateral to the muscle. In (b) the impulse reaches the spinal cord antidromically through the efferent fibre and can then pass from the furst to the second motoneurons either at sites of direct apposition or by spinal collaterals.

ing pelvic muscle have been described,,$^{14-16}$ and the same oppositions also exist in humans. ${ }^{7}$ Such extensive contacts have been proposed to be a morphological substrate for electronic interaction. Both of the mechanisms mentioned by Gogan et al ${ }^{12}$ could be involved in the second anal response and both would result in the polyphasic EMG pattern observed.

This work was supported by a grant from the Danish Multiple Sclerosis Society.
' Rossolimo G von. Der Analreflex, seine Physiologie und Pathologie. Neurologisches Centralblatt 1891;9:2579.

${ }^{2}$ Pedersen E, Harving H, Klemar B, Tørring J. Human anal reflexes. J Neurol Neurosurg Psychiatry 1978;41:813-8.

${ }^{3}$ Tørring J, Pedersen E, Klemar B. Standardization of the electrical elicitation of the human flexor reflex. $J$ Neurol Neurosurg Psychiatry 1981;44:129-32.

${ }^{4}$ Henry MM, Swash M. Assessment of pelvic-floor disorders and incontinence by electrophysiological recording of the anal reflex. Lancet 1978;1:1290-1.

${ }^{5}$ Henry MM, Parks AG, Swash M. The anal reflex in idiopathic faecal incontinence; an electrophysiological study. Br J Surg 1980;67:781-3.

- Pedersen E, Klemar B. Recording of physiological measurements based on video technique. Scand $J$ Rehab Med 1974;suppl. 3:45-50.

${ }^{7}$ Schrøder HD. Onuf s nucleus X: A morphological study of a human spinal nucleus. Anat Embryol (Berl) 1981;162:553-653.

${ }^{8}$ Tørring J, Søgaard I, Pedersen E, Klemar B. Selective sacral rootlet rhizotomy in the treatment of hyperactive neurogenic bladder. Technique and results. Proceedings. Eleventh Annual Meeting, Lund. International Continence Society. (eds. T. Sundin and A. Mattiasson). Skogs, Trelleborg, 1981, pp. 54-55.

9 Chantraine A, Leval J de, Onkelinx A. Motor conduction velocity in the internal pudendal nerves. In: Desmedt JE, ed. New Developments in Electromyography and Clinical Neurophysiology. Basel: Karger, 1973;vol. 2:433-38.

${ }^{10}$ Veale JL, Mark RF, Rees S. Differential sensitivity of motor and sensory fibres in humans ulnar nerve. $J$ Neurol Neurosurg Psychiatry 1973;36:75-86.

${ }^{11}$ Stålberg E, Trontelj JV. Demonstration of axon reflexes in human motor nerve fibres. J Neurol Neurosurg Psychiatry 1970;33:571-79

${ }^{12}$ Gogan P, Gueritaud JP, Bossavit GH, Tyc-Dumont S. Direct excitatory interactions between spinal motoneurones of the cat.J Physiol 1977;272:755-67.

${ }^{13}$ Cullheim S, Kellerth J-O, Conradi S. Evidence for direct synaptic interconnections between cat spinal $\alpha$-motoneurons via recurrent axon collaterals: A morphological study using intracellular injection of horseradish peroxidase. Brain Res 1977;132:1-10.

${ }^{14}$ Kerns JM, Peters A. Ultrastructure of a large ventrolateral dendritic bundle in the rat ventral horn. $J$ Neurocytol 1974;3:533-55.

${ }^{15}$ Konishi A, Sato M, Mizuno N, Itoh K, Nomura S, Sugimoto T. An electron microscope study of the areas of the Onuf's nucleus in the cat. Brain Res 1978;156:333-8.

${ }^{16}$ Schrøder HD. Organizing of the motoneurons innervating the pelvic muscles of the male rat.J Comp Neurol 1980;192:567-87. 